University of Nebraska - Lincoln

DigitalCommons@University of Nebraska - Lincoln

Valery Forbes Publications

Papers in the Biological Sciences

2009

\title{
The Potential for the Use of Agent-Based Models in Ecotoxicology
}

Christopher J. Topping

University of Aarhus, Rønde, Denmark, cjt@dmu.dk

Trine Dalkvist

University of Aarhus, Rønde, Denmark

Valery E. Forbes

University of Nebraska-Lincoln, veforbes@umn.edu

Volker Grimm

Helmholtz Centre for Environmental Research-UFZ, Leipzig, Germany, volker.grimm@ufz.de

Richard M. Sibly

University of Reading, r.m.sibly@rdg.ac.uk

Follow this and additional works at: https://digitalcommons.unl.edu/biosciforbes

Part of the Pharmacology, Toxicology and Environmental Health Commons

Topping, Christopher J.; Dalkvist, Trine; Forbes, Valery E.; Grimm, Volker; and Sibly, Richard M., "The Potential for the Use of Agent-Based Models in Ecotoxicology" (2009). Valery Forbes Publications. 22. https://digitalcommons.unl.edu/biosciforbes/22

This Article is brought to you for free and open access by the Papers in the Biological Sciences at DigitalCommons@University of Nebraska - Lincoln. It has been accepted for inclusion in Valery Forbes Publications by an authorized administrator of DigitalCommons@University of Nebraska - Lincoln. 
Published in J. Devillers (ed.), Ecotoxicology Modeling, Emerging Topics in Ecotoxicology:

Principles, Approaches and Perspectives 2, pp. 205- 235; doi: 10.1007/978-1-4419-0197-2_8

Copyright (C) 2009 Springer Science+Business Media, LLC. Used by permission.

\title{
The Potential for the Use of Agent-Based Models in Ecotoxicology
}

\author{
Christopher J. Topping, Trine Dalkvist, Valery E. Forbes, \\ Volker Grimm, and Richard M. Sibly
}

Corresponding author - C. J. Topping, Department of Wildlife Ecology and Biodiversity, National Environmental Research Institute, University of Aarhus, Grenåvej 14, DK-8410 Rønde, Denmark; e-mail cjt@dmu.dk

\begin{abstract}
This chapter introduces ABMs, their construction, and the pros and cons of their use. Although relatively new, agent-based models (ABMs) have great potential for use in ecotoxicological research - their primary advantage being the realistic simulations that can be constructed and particularly their explicit handling of space and time in simulations. Examples are provided of their use in ecotoxicology primarily exemplified by different implementations of the ALMaSS system. These examples presented demonstrate how multiple stressors, landscape structure, details regarding toxicology, animal behavior, and socioeconomic effects can and should be taken into account when constructing simulations for risk assessment. Like ecological systems, in ABMs the behavior at the system level is not simply the mean of the component responses, but the sum of the often nonlinear interactions between components in the system; hence this modeling approach opens the door to implementing and testing much more realistic and holistic ecotoxicological models than are currently used.
\end{abstract}

Keywords: Population-level risk assessment, ALMaSS, Pattern-oriented modeling, ODD, Multiple stressors

\section{Introduction}

This chapter is intended to provide some background on agent-based models (ABMs) and the potential for their use in ecotoxicology. This is achieved by a mixture of examples and minireview of ABM issues; it is, therefore, intended

Christopher J. Topping, Trine Dalkvist• Department of Wildlife Ecology and Biodiversity, National Environmental Research Institute, University of Aarhus, Grenåvej 14, DK-8410 Rønde • Center for Integrated Population Ecology, Roskilde University, PO Box 260, 4000 Roskilde, Denmark

Valery E. Forbes • Center for Integrated Population Ecology, Roskilde University, PO Box 260, 4000 Roskilde, Denmark - Department of Environmental, Social and Spatial Change, Roskilde University, PO Box 260, 4000 Roskilde, Denmark

Volker Grimm • Department of Ecological Modeling, Helmholtz Center for Environmental Research - UFZ, Permoserstr. 15, 04318 Leipzig, Germany

Richard M. Sibly • Center for Integrated Population Ecology, Roskilde University, PO Box 260, 4000 Roskilde, Denmark • School of Biological Sciences, University of Reading,Whiteknights, Reading RG6 6PS, UK 
as a primer for those interested in further exploring this type of modeling in ecotoxicology.

Ecotoxicology has, in common with the majority of the natural sciences, followed the basic principles of analytic thinking whereby the whole is abstractly separated into its constituent parts in order to study the parts and their relationships. This approach to science works for physical systems such as those typically studied in physics or chemistry, but may not always be the optimal approach for biological systems with their innate complexity and interactions. For example, in the case of evaluating the impact of stressors on biological systems there is clearly a great difference between the response of animals in the laboratory, given a precisely measured and timed dose of toxicant, and the populations of the same animals moving through a real-world situation of spatiotemporal variability in toxicant concentration, interacting with each other and the biotic and abiotic components of their environment.

It is in fact rather difficult to see how the abstract laboratory test can easily be related to impacts at the population level. Following this train of thought suggests that in order to properly understand this kind of system we should perhaps embrace its complexity rather than ignore it. This means treating a system as an integrated whole whose properties arise from the relationships between the system components rather than studying the components in isolation, thus shifting from the importance of elements to the importance of organizational pattern, i.e., applying a systems approach. Luckily, the use of ABMs opens up the potential for doing just this.

\subsection{What Is an ABM?}

An ABM is a computational model for simulating the actions and interactions of autonomous individuals in a defined virtual world, with a view to assessing their effects on the system as a whole. This is clearly analogous to integrating the response of individuals into a population response that, when considering impact assessment in ecotoxicology, is the level at which interest and protection goals are usually aimed.

Of course, there are many models of ecological populations and many approaches, but there are a number of characteristics of ABMs that set them apart from other more traditional approaches. These characteristics can be broadly described as being their explicit consideration of spatiotemporal variability and their ability to include individual behavior, with population responses being emergent features. Thus, animal behavior such as patterns of movement can be simulated so that a dispersing animal moves in very different ways depending upon its type (e.g., bird, mouse, beetle, human). This provides a huge predictive potential compared with more aggregated approaches.

These properties have resulted in the use of ABMs in a wide and steadily increasing range of applications. In 1996, there were 31 agent-based papers published (source: ISI Web of Knowledge), but by 2006 the number had risen to 494. Some varied examples include simulations of immune system responses to perturbations [1], of ethnic diversity in economically and spatially structured neighborhoods [2], of entry and exit routes to a baseball stadium under a range 
of conditions including simulation of terrorist attack [3], and of urban evacuation strategies [4]. Current use of ABMs in ecotoxicology is limited, but their usage in related areas is increasing. Recent developments include models of whale watching by tour boats, including evaluation of the risks to the whale population [5], epidemiology (e.g., [6, 7]), the exploitation of limited renewable resource [8], and conservation [9-11]. ABMs help understand biological systems because, unlike physical systems, there is heterogeneity in their components, and this heterogeneity affects the overall dynamics of the system $[12,13]$ in short because variation in space and time matters in biological systems and ABMs deal with this very well.

In ecology, ABMs developed somewhat independently of other disciplines and are often referred to as "individual-based models" (IBMs). The distinction is, however, of little importance today, and Grimm [14] suggests not distinguishing IBMs and ABMs any longer and using both terms interchangeably. Originally the term IBM was used to emphasize the discreteness of individuals, heterogeneity among individuals, and local interactions, rather than adaptive decision making and behavior, which have been the main drivers in the development of ABMs $[12,15]$. Recently however, IBMs and ABMs have merged into one big class of models [16], covering a wide range from very simple to rather complex models [17].

In this chapter, we focus on "full-fledged" ABMs, which include realistic landscapes, a high temporal and spatial resolution, individual heterogeneity, local interactions, adaptive behavior, and often also different species. This is, in terms of development time and resources needed for testing and parameterization, the most demanding type of ABMs, but also the most powerful one if it comes to the potential to validate these models and to use them for predictions of environmental scenarios that so far have not been observed. It should be kept in mind, however, that more simple ABMs also have their place in basic and applied ecology, including ecotoxicology (e.g., [18]).

\subsection{Constructing ABMs}

ABMs can be significantly more demanding to develop than other population models. Development starts with the creation of a conceptual model of the system of study comprising the basic simulation goals, elements of the system and their behaviors, and the endpoints of interest [16, 19]. Depending upon the goals of the model, it may utilize designed or empirically grounded agents and environments, and choices here may have significant implications for results, as we now show.

In early ABMs structural environment into which the agents are placed was created using regular geometric shapes, but it is now known that the use of unrealistic structural environments may bias results [20], and a similar argument can be made for simplification of the behaviors of agents [21]. Another problem that the ABM developer may face, which is not a problem for traditional modeling approaches, is that of concurrency. Concurrency problems occur when objects interact, especially if their interaction is controlled via some limiting resource. A good example of this is the well-known model by DeAngelis et al. [22] where wide- 
mouthed bass interact indirectly through their Daphnia food resource and directly by eating each other. By not taking account of concurrency issues the positive feedback loops emergent in the model were strengthened (see [23] for a discussion of this effect and concurrency issues in ABMs). Concurrency issues are not critical to all ABMs but in cases where they are they can increase the complexity of model design. Scheduling of the model's processes and the exact mode of updating the model's state variables are thus critical and need to be planned and communicated carefully [24, 25].

It will by now be apparent that the increase in realism made accessible by ABMs comes at a cost, both in terms of potentially huge data requirements, but also in terms of the technical ability required for model construction. However, the technical problems are eased by the emergence of software tools. Thus, models may be created using ABM "platforms," that is, libraries of predefined routines such as REPAST [26], NetLogo [27], and SWARM [28]. Models of limited complexity can be developed using these platforms, whereas more complex or computationally demanding models are usually implemented in more efficient low-level object-oriented languages such as C++ or Java. Animal, Landscape, and Man Simulation System (ALMaSS), a framework for ABMs for pesticide risk assessment [29], which is used as an example throughout this paper, was written in $\mathrm{C}++$ since run times are very long, and shaving tiny fractions of seconds from loops can save many hours of simulation time with millions of agents.

While simple systems can be built by anyone of average programming ability, the effectiveness of larger scope and more realistic models depends on the ability of the programmer to code efficiently. At this level of software engineering there is a whole new skill set required by the ABM developer. For example, sorting routines are common constructs in ABMs but vary hugely in their efficiency, so choices here may dramatically affect overall runtimes. There is also the problem of code reliability. With large and complex models the scope and complexity of errors increases and code maintenance and debugging tasks can mushroom out of all proportion. This is particularly the case with highly complex multiagent communication such as between flock or family members, and it has cost many weeks of debugging in ALMaSS. Coping with such problems requires familiarity with basic computing science principles. Hence, the optimal solution is that the modeler also possesses software engineering skills, which will not only speed up the development cycle, but will also improve the model design by ensuring good code structure at an early phase. However, while there is an increase in the number of computational biologists being trained, this skill combination is still rare. Grimm and Railsback [16] therefore recommend considering close collaborations of ecological modelers and computer scientists where, however, the modeler should keep full control of the software, that is, not depend on the computer scientist to use the software and modify it.

Unfortunately no simple introduction to building ABMs currently exists. There are many good object-oriented tutorials available however, and these, combined with an understanding of the philosophy of the approach, are a good place to start. Detailed advice can be found in Grimm and Railsback [16] who provide an introduction to what they term "individual-based ecology," which encompasses the use and development of ABMs. 


\section{Examples Illustrating the Use of ABMs}

We here present examples selected to illustrate some of the facets of using ABMs, and some of the interesting results that can emerge. The series of example applications used to illustrate the potential of ABMs in ecotoxicological research utilize a single ABM system, ALMaSS [29]. In these examples space limits a description of the manner in which conclusions were drawn, but in all cases this was by carrying out additional exploratory simulations to test the behavior of the system under different conditions, as well as detailed analysis of outputs in the light of knowledge of the model structure. In addition, we will briefly introduce two further families of ABMs, which were not developed for ecotoxicology, but which very well illustrate both the high costs for developing full-fledged ABMs and their striking predictive power, once their testing has been completed.

\subsection{Introduction to ALMaSS}

ALMaSS was designed as a system to evaluate the impact of human management of landscapes on key species of animals in the Danish landscape. ALMaSS was not created with a clearly focused goal in mind but to be a highly flexible system capable of simulating a wide range of interactions between landscape structure, management, and animal ecology. Thus, ALMaSS is a flexible system for implementing ABMs of selected species, with the aim of predicting the impact of changes in management of the Danish landscape.

ALMaSS can be separated into two main components: the landscape and animal models. The landscape comprises a topographical map, together with strategies of human management (primarily farming but also other management such as mowing of roadside verges), traffic and road networks, weather, submodels for calculating arthropod biomass, models for general vegetation and crop growth, and also models of the environmental fate of pesticides. These submodels and processes are updated on a daily basis during the simulation and provide the potential to model factors such as farm and crop management in great detail. The farm management modules permit the definition of different farm types each with their specific crop choices and type of management (e.g., conventional pig, arable, and dairy production, and organic variants of these).

Each farm mapped in the landscape is allotted a farm type and the farm manager, also an agent, applies management to his fields in terms of sowing crops and subsequent crop husbandry while reacting to weather and soil conditions. Crop husbandry is highly detailed (see [30]) and simulates all farming activities that would be carried out on that crop (e.g., plowing, harrowing, sowing, fertilizer applications, pesticide applications, harvest, and postharvest operations). Application of pesticides and fertilizers can be allocated specific characteristics (e.g., amount and type) and may result in changes in the vegetation growth, arthropod biomass, and provide field-specific information for animal models such as the type and amount of toxicant present. 
The topographic map utilized by the landscape has a resolution of $1 \mathrm{~m}^{2}$ and typically covers an area of $100 \mathrm{~km}^{2}$. Combining this map with the management information, weather and vegetation growth information creates a virtual reality into which the animal models are placed. The animal models are agents designed to simulate the ecology and behavior of individual animals as closely as possible. Each agent moves around in its virtual world in much the same way that a real animal moves in the real world, picking up information from its surroundings as it goes and acting upon this in order to feed and ultimately reproduce. Changes to the agent's environment occur on a daily basis as weather changes, vegetation grows, or the farmer manages a field.

A number of animal models exist for ALMaSS. Those used as examples here are Alauda arvensis (skylark) [30, 31], Microtus agrestis (field vole) [29], Bembidion lampros (beetle) [32], Erigone atra/Oedothorax fuscus (spider) [33], and Capreolus capreolus (roe deer) [34]. These range from species with highly detailed behavior but low numbers (roe deer) to spiders with simple behavior but the necessity to handle over 1 million agents concurrently. However, all models conform to a basic framework, essentially a state machine, whereby:

- Each animal has an initial state that is a behavioral state.

- There is a set of possible input events.

- Transitions to new behavioral states depend on input events.

- Actions (output events) are determined by behavioral state and environmental opportunities.

Each agent will cycle through this state machine at least once per simulation day and potentially many times depending upon the inputs and outputs. For example, a vole in the state "explore" may explore his surroundings, resulting in the input that there is no food, and make a transition to the new state "dispersal"; this results in the action of dispersal that then triggers a transition to the state "explore." This cycle may repeat itself until the vole finds food, dies, or runs out of time that day (Figure 1). Inputs may also occur as events, not under the control of the animal. For example, if our dispersing vole is run over by a car it will make

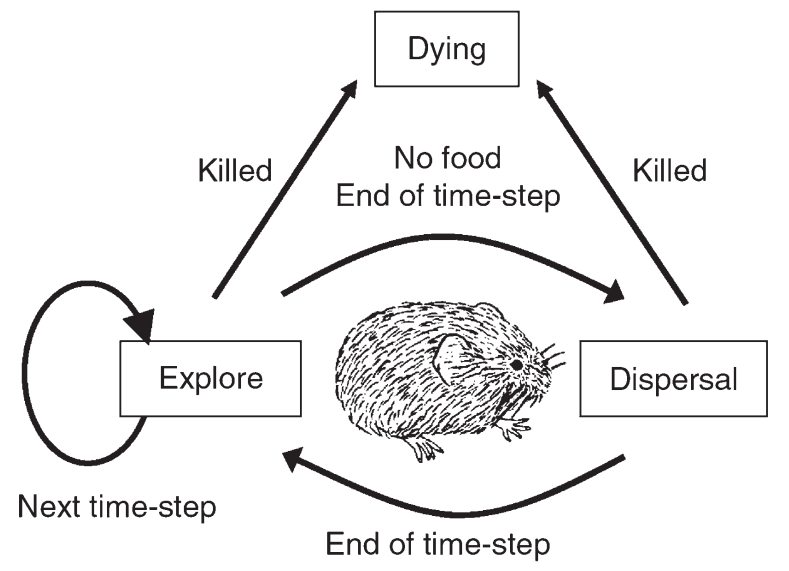

Figure 1. A diagram of a fragment of the field vole state machine. States are denoted with boxes, transitions by arrows. See text for further explanation. 
an immediate transition to the state "dying." This event-driven interaction is also the basis for modeling topical exposure to pesticide applications, meaning that an animal may only be exposed if it is in the location where the pesticide is sprayed at the time it is sprayed.

A system such as ALMaSS has a number of potential uses in ecotoxicology. These can broadly be divided into three main categories:

- Policy scenario analysis: This utilizes the capability of the agent-based system to respond to changing inputs. For example, how will pesticide usage be affected by specific taxation measures? (see examples 1 and 4 later). Taxation is an input to the model that causes changes in farmer behavior, which result in changed patterns of pesticide use. Since the animals react to pesticides as they find them in their day-to-day activity, their behavior in turn is affected, and the sum of their behaviors results in a population response that can be evaluated.

- Risk/impact assessment and regulation: Scenarios of application of pesticides with specified properties are studied and population responses are evaluated (see examples 2 and 3). The challenge here is to define specific yet representative scenarios, since a greater range of factors is analyzed than is traditional in this area.

- Systems understanding: Perhaps the most important use of ABMs in ecotoxicology is to improve our understanding of the ecological systems and how they are affected by pesticides. ALMaSS is able to use a systems approach to investigate system properties that would be impossible or exceedingly difficult to study in real life (see examples 1-4).

\subsection{Example 1: Impacts of Mechanical Weeding on Skylark Populations}

Pesticide use has been an important factor in the decline of a range of European farmland bird species over the last 20 years, primarily via indirect effects on wild plants and arthropods $[35,36]$. It is, therefore, desirable to use pesticides less, but policies directed toward this need to be based on good advice. With this background Odderskær et al. [37] set out to evaluate the potential impact of replacing herbicide use with mechanical weeding on inter alia skylark populations. Mechanical weeding is rarely used in conventional farming, despite its well-documented effectiveness, so there is little opportunity for observational study. The goal of the ALMaSS modeling was to assess the direct or indirect impact of mechanical weeding on birds reproducing in fields where it is applied. The problem was tackled in two stages: the first an experiment to assess the lethality of mechanical weeding to skylark nests, and the second to assess potential impacts of different management scenarios.

A range of scenarios were simulated (see [37]) but those that show the clearest results are experimental scenarios where the assumption is that all farmers in the landscape grew a single monoculture crop. Figure 2 shows the number of nests, nests with eggs (under incubation), and nests with young, which were destroyed when mechanical weeding was used in monoculture spring barley on either the 

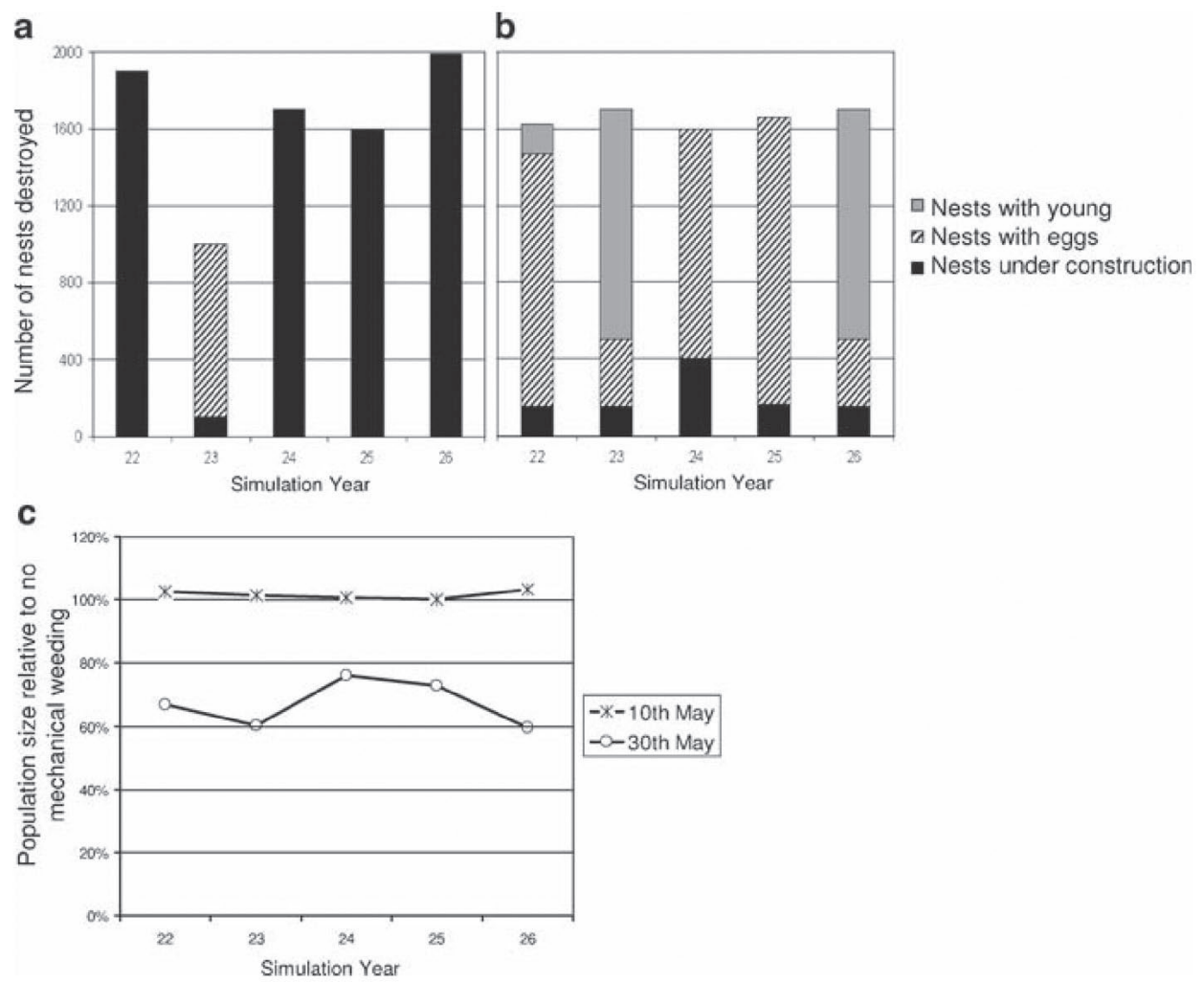

Figure 2. Example 1: ALMaSS scenario results. (a) The number of nests destroyed by mechanical weeding on 10th May. (b) The number of nests destroyed by mechanical weeding on 30th May. (c) The population-level impact of mechanical weeding shown relative to a no mechanical weeding situation.

10th or 30th of May, which corresponds to mid- or late-season application. Although variable with year and therefore weather, late-season use destroyed a very large number of nests containing eggs or young, whereas the earlier application largely affected nests during nest building or egg-laying. The skylark population was consequently much reduced by late application (24-40\%) whereas earlier application resulted in a slight increase of up to $3 \%$. This increase is surprising and the model was neither specifically designed nor calibrated to make this prediction, which, therefore, can be considered an independent or secondary prediction (sensu [16]). Moreover, an ABM does not require us to just believe in the results as a black box, but allows us to try and understand why certain things happen. In this case, closer analysis of the model revealed that due to the rapid growth of the cereal crop the skylark has only a limited window of breeding opportunity between emergence and canopy closure [38-40] and is often limited to just one breeding attempt. Since the first clutch of the season is usually one egg smaller than the second clutch in this species, the early loss of a clutch was a slight benefit if the second brood could be completed before the breeding window closed. Broods lost due to weeding on 30th May (40 days from sowing) could not be replaced within the window of opportunity. These results led Odd- 
erskær et al. [37] to recommend that mechanical weeding be used up to a maximum of 30 days after sowing to avoid significant risk to skylark populations. The recommendation was not with respect to a calendar date, because it is timing with respect to the breeding window that is critical. In a subsequent independent field study [41], it was found that mechanical weeding 35 days or later after sowing caused significant reduction in skylark breeding in spring cereals. Thus, the prediction of the model was confirmed indicating that key elements of the skylark's population dynamics were captured in the model, that is, the model was structurally realistic [42].

\subsection{Example 2: Risk Assessment for Beetles and Spiders Including Multiple Stressors}

Regulatory authorities have strict procedures for assessing whether a pesticide presents an unacceptable risk to nontarget organisms. For example, according to EU directive 91/414 and its annexes and guidance documents, if the toxicity exposure ratio (TER) is $<5$, "no authorization shall be granted, unless it is clearly established through an appropriate risk assessment that under field conditions no unacceptable impact occurs after the use of the plant protection product under the proposed conditions of use" (Annex VI of EU Directive 91/414/ EEC). While this criterion may seem objective and stringent it is also administratively inflexible and simplified. In this example, we demonstrate how misleading the criterion can be by evaluating pesticide impact with and without other mortality factors (multiple stressors) and by using test species with slightly differing characteristics.

ALMaSS scenarios were created using the following assumptions:

- An insecticide was applied to cereals.

- Treated cereals received from one to three applications each year in late May to July following normal farming practices for insecticides.

- No other pesticides were used anywhere in the landscape (the current regulatory standpoint).

- Exposure to the pesticide resulted in $90 \%$ mortality for all exposed beetle and spider life-stages.

- Exposure occurred when the organism was present in the field on the day of pesticide application, and all organisms present were considered to be exposed.

- Residues were not assumed to have any impact, hence only direct exposure to spray was considered toxic.

- There was no drift to off-crop areas.

- The landscape considered was a $10 \mathrm{~km} \times 10 \mathrm{~km}$ area of Denmark near the town of Bjerringbro (56 $22^{\prime} \mathrm{N}$; $9^{\circ} 40^{\prime} \mathrm{E}$ ) (Figure 3).

Three factors were varied:

- The proportion of the landscape exposed was altered by assuming that insecticide was applied to $0,25,50$, and $100 \%$ of cereal fields, and that all arable fields grew cereals. 


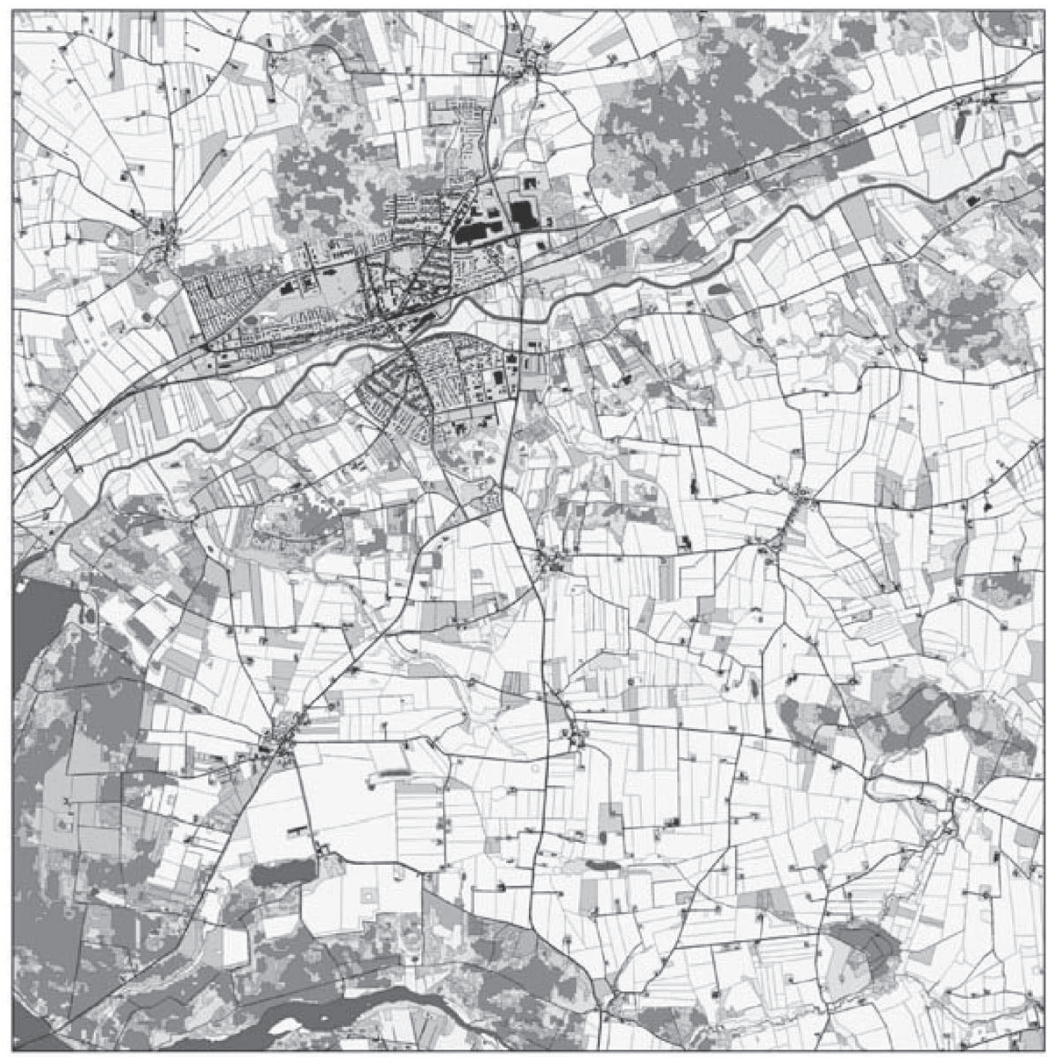

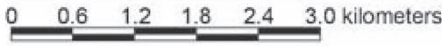

\begin{tabular}{|l}
\hline \\
Building \\
Urban area \\
Road \\
Roadside verge \\
Field \\
Pasture \\
\hline$\square$ Permanent pasture \\
Deciduous forest \\
Conifereous forest \\
Conifereous - young trees \\
Mixed forest
\end{tabular}

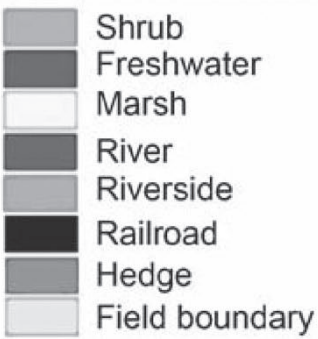

Figure 3. A GIS representation of the Bjerringbro area in central Jutland, Denmark. This is the landscape used in all ALMaSS examples.

- The implications of assumptions about other mortality factors were investigated by running four scenarios - one where the impact of soil cultivation and harvest mortalities was assessed in the absence of pesticide (scenario BM in Figure $4 b$ ), a second scenario where only pesticide mortalities were incorporated and soil and harvest mortalities were ignored (scenario PM), and a third scenario where the impact of the pesticide was assessed against a back- 
a
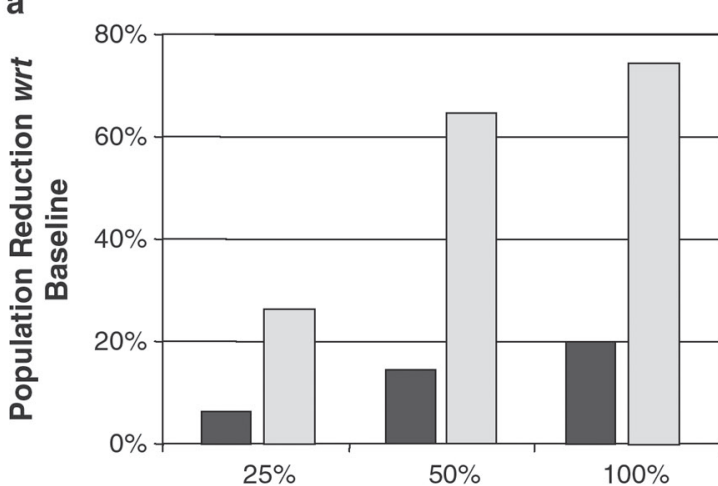

Fast Beetles

$\square$ Slow Beetles

Proportion of fields treated

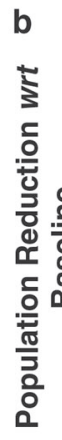

$100 \%$

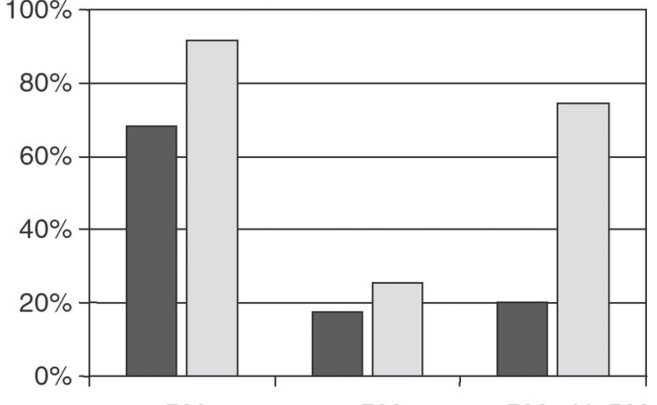

Fast Beetles

$\square$ Slow Beetles

BM

PM

PM with BM

Mortality Assumptions

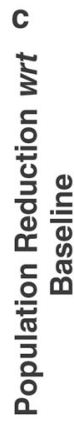

$100 \%$

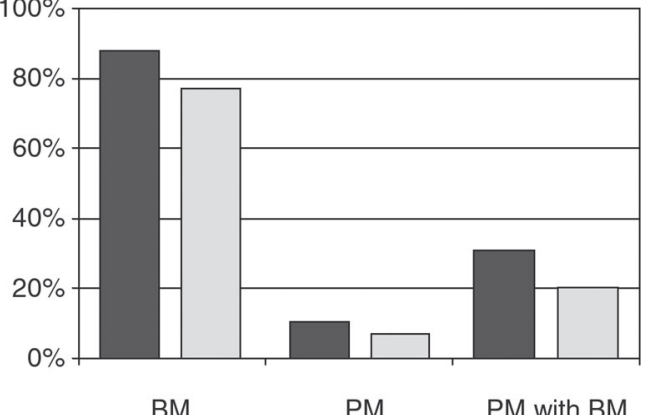

BM

PM

$\mathrm{PM}$ with $\mathrm{BM}$

O. fuscus

$\square$ E. atra

Mortality Assumptions

Figure 4. Example 2: ALMaSS scenario results. Population reductions are expressed as a percentage of those in the baseline scenario (see text). (a) The size of population reduction in relation to the area treated with insecticide, for fast and slow moving beetles. (b) The size of population reduction of fast and slow beetles, $\mathrm{BM}=$ only agricultural operation mortalities, $\mathrm{PM}=$ only insecticide mortality, $\mathrm{PM}$ with $\mathrm{BM}=$ pesticide mortality assessed against a background of agricultural operation mortality. (c) Same as (b) but for two species of spider. 
ground of including the soil cultivation and harvest mortalities (scenario BM with PM). Values for mortalities were available from [43], and all arable fields were assumed to grow cereals and have insecticide applications. A fourth scenario was run without pesticide or soil cultivation and harvest mortality and was used as a baseline for the results presented in Figure 4.

- Variation in species life history was assessed in two ways. A very simple change to the beetle model was made by changing the maximum daily movement rate used by [32] to be 10 or $20 \mathrm{~m}$ per day (slow and fast beetles). The second assessment was made using models of two species of linyphiid spider (Erigone atra and Oedothorax fuscus), both with similar habitat requirements and both common agricultural species but differing in their breeding behavior and dispersal. O. fuscus has a shorter breeding season and lower dispersal ability than E. atra.

Twenty replicates were obtained of all scenarios with scenario runs of 55 years. The first 11 years were discarded as a burn-in period, and the results were expressed as mean population size over the last 44 years. Weather data were as used by Topping and Odderskær [30] and were a continuous loop of 11 years of weather data from a weather station near to the landscape simulated.

Results - For clarity all results are expressed as the size of the population reduction compared with a baseline scenario. Increasing the area treated with insecticide reduced beetle population size, but the effect was much more severe if the beetles moved slowly (Figure 4a). Smaller differences were observed between fast and slow beetles in terms of their sensitivity to background and pesticide mortalities (scenarios BM, PM, and BM with PM, Figure $4 \mathrm{~b}$ ), nor was there much difference in the responses of the two spider species (Figure 4c). Background mortalities were generally high and much higher than those caused by the pesticide impact alone. However, if we evaluate the effects of the pesticide while controlling for background mortalities (i.e., BM vs. PM with BM) then in all cases the impact of the pesticide was greater than measured without other mortalities, and in the case of the less mobile beetle and spider it was almost four times greater.

The results demonstrate two effects. The first is that mobility clearly interacts with the pesticide application, and therefore we can get widely differing results with different life-history strategies. This effect has been shown in the real world in carabid beetles [44] and is partly due to mobile beetles and spiders being able to "leapfrog" disaster by moving from field to field and therefore having a greater probability of not being sprayed, but largely due to the faster recovery potential of mobile animals as they reinvade and breed in recently sprayed areas.

The second effect is related to the population dynamics. In cases where mortality on individuals is low the population grows and reaches a level where it becomes self-regulating through density dependence. At this point the impact of lower levels of mortality is to remove many individuals that would have died in any case, equivalent to the doomed surplus of Errington [45]; hence, impacts are lower when seen at the population level. In contrast, a population under heavy mortality, such as slow beetles under soil cultivation and harvest mortalities, is very vulnerable to a small extra mortality because this kills animals that would otherwise have contributed to population growth. 


\subsection{Example 3: Impacts of an Endocrine Disrupter on Vole Populations: Toxicity, Exposure, and Landscape Structure}

As with example 2 with multiple stressors this analysis is derived from a risk assessment, but with the purpose of investigating the components of the assessment to gain an understanding of the field vole population response, rather than conducting a formal risk assessment. Here, we exploit the ability of ALMaSS to incorporate complex patterns of toxicity, to modify different aspects of a pesticide risk assessment, and calculate the population-level response. This flexibility allows the manipulation of all aspects of the risk assessment in an experimental way, using the model as a virtual laboratory to carry out experiments that would be impossible in the real world. Specifically we investigate how changes in toxicology, exposure, and landscape structure alter population responses, to gain insights into the properties of the system. The scenarios we present are illustrative only; for a comprehensive account, see Dalkvist et al. [46].

The toxicology investigated is unusual but closely similar to that of the fungicide vinclozolin, an endocrine disrupter where the effect is inherited epigenetically through the male germline after exposure in the uterus [47, 48]. This toxicology is challenging to model because of the epigenetic component of transmission of effects, and because expression of the toxic effects is chronic. In the model, expression of toxic effect was as either absolute sterility or a halving of the mating success of male offspring. Those with a reduced mating success passed on this genetic trait to their male offspring.

Other than the altered fertility the affected males were assumed to behave as nonaffected individuals since it was not known if the affected voles would change behavior, and the worst case was assumed. However, females mating with sterile males did not experience false pregnancies and would attempt to mate the following day if mating was unsuccessful. This is likely to be a real situation since voles are polygamous, but it is by no means certain that a female will not mate with the same infertile vole again. This depends on which male vole is closest to her at the time of mating, and it is therefore a function of the territorial behavior of the model voles. This polygamous behavior has the result that both inheritance and purging of the epigenetic effect are density dependent. This is because the probability of a nonsterile vole territory overlapping a female's territory increases with vole density. The system thus comprises complex dynamics that would be difficult to study experimentally in the real world, but is amenable to investigation in an ABM.

In all cases scenarios were constructed by modifying a single factor at a time and expressing the results as a population size relative to a baseline scenario where no pesticide was applied. The landscape used was again that shown in Figure 3, but with some fields replaced by orchards, randomly placed until orchards occupied $10 \%$ of the total agricultural land. Landscape structure was modified in later experiments by altering the locations of patches of optimal habitat. Pesticide was applied for 30 years starting in year 31 and was followed by a 60 -year recovery period again where no pesticide was applied. Thirty-five replicates of each scenario were run. For clarity the experimental scenarios were divided into two groups: one to investigate the toxicity and exposure factors and the other to evaluate landscape structural impacts. 


\subsubsection{Toxicity and Exposure Scenarios}

Five scenarios were constructed to evaluate the impact of factors related to toxicology and exposure. These were (1) a "default" scenario with one pesticide application to all orchards on May 31. The other scenarios were constructed by varying one factor at a time of the default scenario, as follows: (2) a "clover/ grass" scenario where the pesticide was sprayed on clover grass fields that replaced orchards, (3) a "two applications" scenario where the orchards had an additional pesticide treatment on 14th June, (4) a "NOEL" (no observable effect level) scenario where the effect level was altered to one quarter of the NOEL in the default scenario, and (5) a " $\mathrm{DT}_{50}$ " scenario where the pesticide half-life was a factor four times longer than that in the default scenario.

\section{Toxicity and Exposure Results}

The population responses differed between scenarios as shown in Figure 5. Taking each scenario in turn:

Clover/Grass: Spraying clover grass instead of orchards resulted in the lowest population depression of all scenarios, and the population reached full recovery within the simulation period. This might seem strange because the field vole lives in grass-vegetated areas that can function both as a continuous food supply and cover [49], and therefore exposure might be expected in a grass crop. However, clover grass fields in the modern intensive agricultural landscape are cut for silage or used for grazing livestock throughout the year, so that the voles' habitat is continually being destroyed. Consequently, these fields are not suitable breeding habitat [50-52], although they facilitate dispersal. Accordingly a small fraction of the voles were exposed to the pesticide in our simulation, resulting in a negligible population depression.

In contrast the orchards contain grass cover between the trees, which in the "default" scenario is cut once a year just before harvest, and voles living here were subject to much less disturbance. This illustrates the importance of the animals' ecology and behavior in risk assessment. It is also interesting to note that the impact at the population level in this scenario was ca. $1 \%$, but that $4 \%$ of all male voles exhibited a toxic response (Table 1 ). Of these $4 \%$ only $22 \%$ carried the paternally transmitted gene, indicating that the voles that were affected were not breeding as successfully as those in other scenarios.

Two applications scenario: A second application to the orchards led to a doubling of the amount of pesticide applied in the landscape, but not a doubling of the population depression or the proportion of affected voles (Figure 5a, b). The explanation is that the second application hits a population containing voles already affected by the first.

NOEL and $\mathrm{DT}_{50}$ (half-life) scenarios: In the NOEL scenario toxicity increased by a factor of 4 , and this resulted in a doubling of population impact than in the 


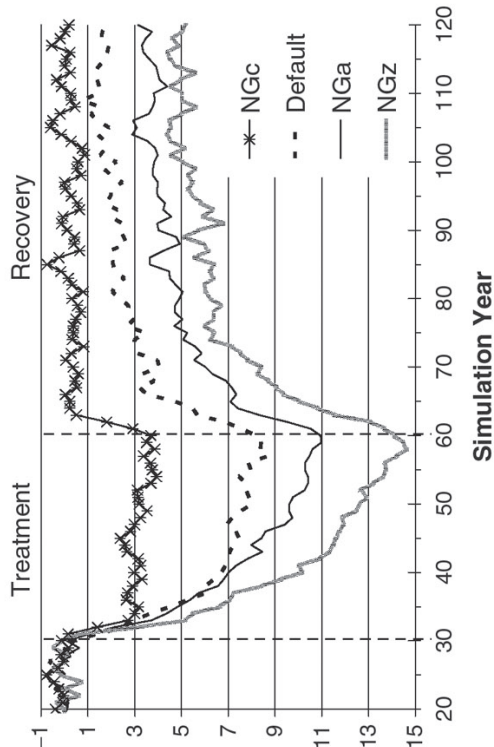

0

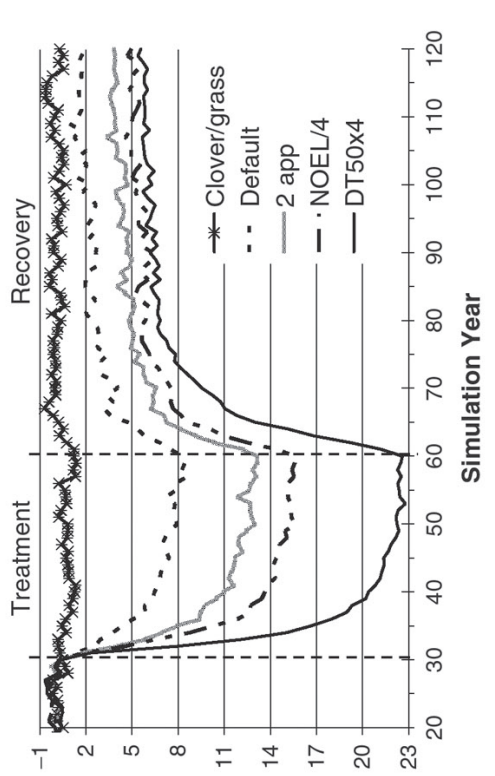

$(\%)$ uo!̣ssesdeg uo!jejndod

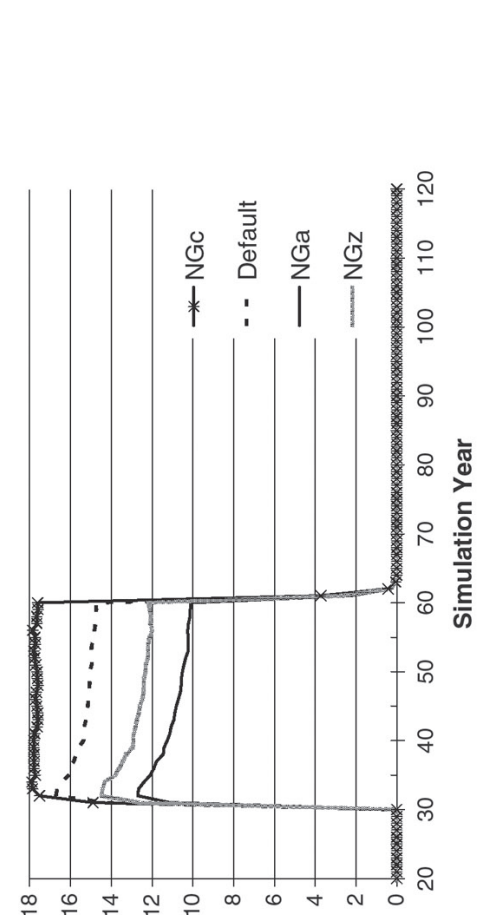

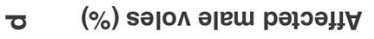

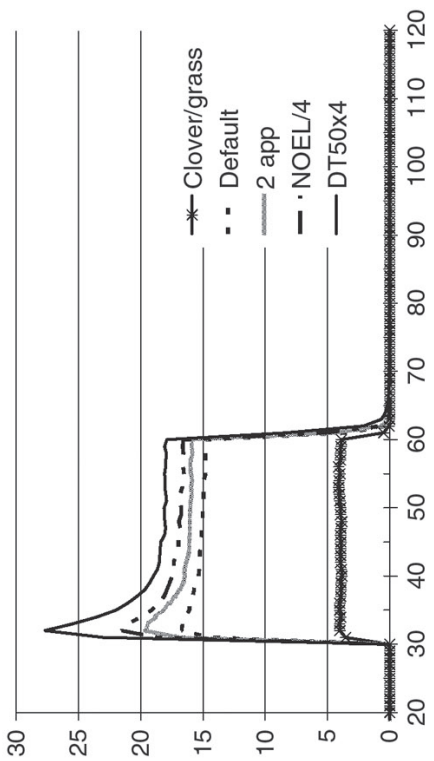

(\%) sәјо ә әеш рәјэән

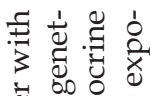

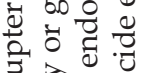

矛艺运

\&

. 듕

号 䒕

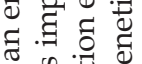

\%

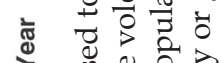

की

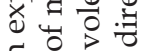

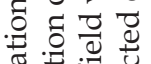

늘

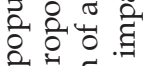

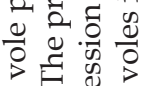

를 음

ㄷํㅇ 듕

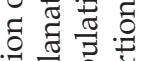

के है है

ข

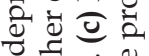

๑苛官

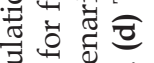

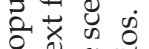

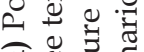

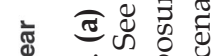

¿ फं क्षे

은 Ð

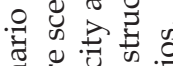

चै ญ्रु के

论

क

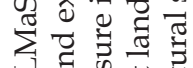

४ तै के

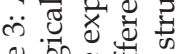

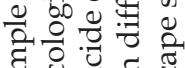

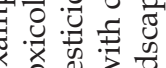

Iิ

ம் 艺氙

원을

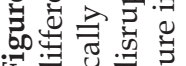


Table 1. Example 3: results of ALMaSS simulations

\begin{tabular}{lrrr}
\hline Scenarios & $\begin{array}{r}\text { Total of } \\
\text { affected } \\
\text { males }(\%)\end{array}$ & $\begin{array}{r}\text { Directly affected } \\
\text { males as a \% } \\
\text { of total affected }\end{array}$ & $\begin{array}{r}\text { Baseline } \\
\text { population } \\
\text { size }(1,000 s)\end{array}$ \\
\hline Clover/grass & 4 & 78 & 58 \\
Default & 15 & 52 & 58 \\
Two applications & 16 & 56 & 58 \\
NOEL/4 & 17 & 59 & 58 \\
$\mathrm{DT}_{50}{ }^{*} 4$ & 18 & 75 & 58 \\
$\mathrm{NG}_{\text {around orchards }}$ & 18 & 54 & 62 \\
NG not around orchards & 10 & 51 & 54 \\
$0 \%$ NG & 12 & 51 & 37 \\
\hline
\end{tabular}

The total proportion of all male voles affected by the endocrine disrupter together with the proportion of those that were directly affected by exposure in the uterus and the total mean size of the vole population in the baseline scenario for each toxicological, exposure, and landscape structural scenarios

default scenario and a higher impact than applying the pesticide twice. However, a fourfold increase in half-life, in the $\mathrm{DT}_{50}$ scenario, had even more impact (Figure 5a). The explanation can be found in the first-order kinetics of decay for the pesticide:

$$
C=C_{0} \mathrm{e}^{-k t} \Leftrightarrow k=-\left(\ln \left(C / C_{0}\right)\right) / t \Leftrightarrow k=\ln 2 / \mathrm{DT}_{50}
$$

where $C$ is the concentration of the residue at time $t ; C_{0}$ is the residue concentration at the start, and $k$ is a rate constant for loss, which is dependent on $\mathrm{DT}_{50}$. By halving $\mathrm{DT}_{50}, k$ is doubled, which increases the coefficient of the exponential curve and so reduces the period of exposure. By contrast changing NOEL is equivalent to changing the constant $C$ in (1), which would result in a small change of the time period of exposure $(t)$ compared with changes in $k$. Thus, the voles are more sensitive to alterations in half-life than to alterations in toxicity. Despite this, half-lives of pesticides receive little attention in current risk assessments.

\section{Toxicity and Exposure Discussion}

The population recovered completely by year 120 only in the Clover/Grass scenario, where a limited proportion of the voles had been affected. This result could have been related to the epigenetic effect of the pesticide, but investigation of the frequency of affected voles showed that the alteration was purged from the population after only a short period (Figure 5b). In fact, the phenomenon was related to the spatial dynamics of the voles in this fragmented landscape. Even small perturbations of the population can mean local extinction for small subpop- 
ulations, and the time before recolonization depends on their location relative to larger source populations. If the perturbation is large, then this effect is exacerbated, resulting in more isolated subpopulations and consequently an elongation of the recovery period (Figure 5a).

The unusual form of the recovery curve was a result of initial logistic population growth in core habitats, followed by delays dependent on dispersal to recolonize other areas that had been lost following pesticide application. The reverse mechanism, together with epigenetic breeding depression, explains the continual decline of the voles during the period of continuous pesticide application, as patches slowly become empty and the vole population contracts to core habitats. This spatial mechanism provides a new dimension to risk assessment since spatial dynamics are currently ignored.

\subsubsection{Landscape Structural Manipulations}

As shown earlier there are indications that the magnitude and effect of pesticide exposure on populations are influenced by the spatial structure of contamination in the landscape and habitat location [53-55]. Even so, the use of nonspatial approaches is still common when characterizing exposures and effects of pesticide stresses. To demonstrate the possible effect of landscape structure in the risk assessment three scenarios were constructed based on the default scenario already described containing randomly allotted primary vole habitat patches ("natural grass" = NG). The natural grassland is a habitat type particularly suitable to the voles because it supplies the animals with food and cover throughout the year. We explored three landscape scenarios as follows: (1) The NG close to the orchards scenario (NGc), where the natural grassland was located around the orchards where pesticide was applied; (2) The natural grass not around orchards scenario (NGa), where the natural grassland was placed away from the orchards; and (3) the $0 \%$ natural grass scenario $(\mathrm{NGz})$, where no natural grassland occurred in the landscape.

\section{Landscape Structure Results}

The NGc scenario resulted in the lowest impact of the landscape scenarios with a population depression of $3 \%$, but the proportion of voles affected by the pesticide was also highest here (Figure 5c, d). This seeming paradox arises because natural grassland in this scenario produced a connected set of suitable habitat fragments capable of sustaining a larger population size around the orchards than in the other scenarios. There were thus sufficient healthy males in the nearby natural grassland to provide viable sperm for females in orchards. This means there were still quite high abundances of voles in the orchards despite these being the sites of exposure of gestating females (Figure 5d), and after spraying these populations recovered rapidly to baseline levels (Figure 5c).

Compared with the NGc scenario the NGz scenario had the highest population depression and lowest recovery level of the landscape structure sce- 
narios. The natural grassland was removed from the landscape completely, thereby reducing connectivity between optimal habitats (which here are primarily the orchards). The affected vole frequency was lower, because of the reduced vole abundance around the orchards, but the impact was higher due to the reduced level of source nontreated populations in the landscape. Accordingly local extinction occurred on a larger scale resulting in the lowest level of recovery.

The NGa was used as a control for the NCc scenario, maintaining the area of grassland but locating it away from the orchards. Voles living in those grasslands were unaffected by the spraying, thus the proportion of affected voles was lower than in the default scenario (Figure $5 \mathrm{~d}$ ), but the population depression was greater (Figure $5 \mathrm{c}$ ) because of a lack of healthy males in grasslands adjacent to orchards to provide viable sperm for females in the orchards. The lack of correlation between three different endpoints, namely, the total proportion of males affected, the proportion of these directly affected, and the baseline population size illustrates the nontrivial nature of the relationships between the factors considered (Table 1).

\subsection{Example 4: Impacts of Pesticide Bans and Reductions at Landscape Scales}

Jepsen et al. [21] utilized ALMaSS to evaluate the impact of a total pesticide ban on the abundance and distribution of five species: Alauda arvensis (skylark), Microtus agrestis (field vole), Bembidion lampros (beetle), Oedothorax fuscus (linyphiid spider), and Capreolus capreolus (roe deer). While it would be temptingly simple to create a scenario where, on the one hand, we had conventional agriculture and on the other the same thing but with no pesticides, this may be a rather too simple approach. Instead, a more holistic consideration of the problem is required. The debate surrounding the safe use of pesticides in Denmark prompted the establishment of a state-funded Pesticide Committee in 1999. This committee initiated a nation-wide evaluation of the economic and agronomic consequences of a partial or complete ban on pesticide usage in Danish agriculture, the conclusion of which was published by Jacobsen and Frandsen [56].

The results suggest that a total pesticide ban will have wide-reaching consequences for land use and also crop choices. For instance, under the EU CAP regulations relating to arable area payments at the time, farmers could claim payments and make a profit by sowing a crop they would never harvest. In other areas land would shift from arable to dairy production. In those areas where arable production remained there would be a reduction in areas of pesticide-intensive crops for harvest. In particular, a significant rise in the area of oil seed rape was indicated since this is cheap to sow and provides a good weed-suppressing cover. Jepsen et al. [21] simulated this outcome by comparing the distribution and abundance of the five species between agricultural practice as in 2003 and a scenario in which all crops were grown organically and where agricultural land altered its composition from 64 to $29 \%$ cereals, oil seed rape increased from 11 to 
$17 \%$ of the arable area, and where roughage (rotational grass, peas, etc.) increased from 19 to $59 \%$, with the remaining areas being set aside. These simulations used the landscape of Figure 3.

As expected due to reduced incidence of crop-management related stressors (insecticides and soil cultivation), beetle and spider numbers generally increased over the whole landscape. Field vole numbers also increased marginally and uniformly because of the increase in connectivity due to increasing the area of grass relative to arable fields. The skylark however, contrary to initial expectations, decreased in population size across the landscape with marked decreases in previously good habitats. These decreases were an integration of a number of positive and negative influences. The reduction in pesticides and subsequent increase in invertebrate food worked positively; however, the lack of tramlines caused by late-season pesticide applications meant that the food was less abundant. In addition, the grass areas would be grown for silage and would have very narrow windows of breeding opportunity before cutting and/or grazing resulted in them being useless as breeding habitat.

The response of the roe deer was also complex with a distinct spatial pattern to the changes. These local population changes were in response to changing crop locations relative to suitable wooded habitats, primarily hedgerows. In those areas where both hedgerows and suitable crops coincided, the deer could move out from woods and forage; in other areas, the lack of shelter meant that the improved forage was not utilized [21].

A similar interaction between pesticide changes and farm management was found when evaluating the impact on skylark population sizes of taxation measures to alter pesticide use [57]. The effects of using pesticides were compared with spraying nothing. The real effect of not spraying would be to not open tramlines, preventing skylark foraging and breeding access, because the farmer would not drive onto the field. Not spraying would also alter the crops grown. When these effects were taken into account the mean $4 \%$ impact of pesticides predicted in an earlier study [30] was reduced to a barely significant $1 \%$ impact [31]. However, in both studies other structural changes in the landscape management were capable of altering skylark populations by $20-50 \%$. We conclude that a common sense, holistic, approach to simulation is needed so that "knockon effects," such as changes in crop area allocations, are taken into account in policy evaluation.

\subsection{Two Further Examples of Predictive, Fully Fledged ABMs}

The development of the ALMaSS framework took 10 years, including program debugging and verifications. The development of a typical animal model with the ALMaSS framework, including testing, usually takes 1-2 years. The analysis of more theoretical scenarios of an existing animal model, however, can be performed rather quickly, typically within a few months. Historically, and due to reasons of page limitations in scientific journals, the extensive testing of ALMaSS so far has not been fully documented. Therefore, we here briefly describe two further fully fledged ABMs that were developed for ecological 
applications and where testing, verification, and validation have already been documented. These examples also show that basing a model on fitness-seeking behavior can make ABMs complex, but highly predictive. The trout model was explicitly developed for management support. The shorebird model has a more academic background but currently is being tailored to address a range of realworld applications.

\subsubsection{Shorebird Models}

The shorebird models of Goss-Custard et al. predict the impact of land reclamation, resource harvesting, and recreation on the winter mortality of shorebirds and waterfowl. The ABMs had to predict the effect of new environmental conditions for which no empirical rules or data were available [58-65].

In these models, the habitat is divided into discrete patches, which vary in their exposure and their quantity and type of food. During each time step birds choose where and on what to feed, or whether to roost. Time steps typically represent $1-6 \mathrm{~h}$. The bird's state variables include foraging efficiency, dominance, location, diet, assimilation rate, metabolic rate, and amount of body reserves. Key environmental inputs to the models are the timings of ebb and flow and temperature. The submodels describing the bird's decision where to move, what to eat, and how much time to spend in feeding are based on principles mainly from optimal foraging theory. The individuals are assumed to always try and maximize fitness, i.e., their own chance of survival.

Model predictions were compared with many observed patterns during several iterations of the modeling cycle. The modeling cycle includes defining the model's purpose, choosing a model structure, and implementing and analyzing the model [16]. At the end of this process, patch selection, prey choice, and the proportion of time spent in feeding were accurately predicted for many species and sites. In one case, the increase in winter mortality due to land reclamation was known from observations. The model was parameterized for the preimpact situation, and then run for the situation after the land reclamation and the increase in winter mortality were determined. The match of observed and predicted increase in winter mortality was strikingly good [66].

\subsubsection{Stream Fish Models}

Railsback and coworkers developed a suite of stream fish ABMs (mainly cutthroat trout Oncorhynchus clarki [67-73]; see also the precursor model of Van Winkle et al. [74]). The models were developed to predict the effects of river management on fish populations. Fish adapt to changes in flow caused by dams and water diversions by moving to different habitat. Thus, to predict how fish populations react to new flow regimes it was necessary to know how fish select habitat. The trout model of Railsback and Harvey [70] uses daily time steps, with stream habitat represented as rectangular cells. The section of a stream represented in the model would usually comprise about $200 \mathrm{~m}$ consisting of about 
100 cells (the number of cells varies because of varying water levels). Within a day, individual fish carry out the following actions: spawn, move, feed, and grow. Mortality could occur within each of these steps and model runs cover a time span of years or decades.

In the model, trout based their daily decision on the projection of current habitat conditions for 90 days into the future [67]. Railsback and Harvey [71] show that this "state-based, predictive" theory of habitat selection is, in contrast to alternative theories, capable of reproducing a set of six patterns observed in reality ("pattern-oriented modeling," [16, 75]). In a management application, the trout IBM was used to predict the population-level consequences of stream turbidity (Harvey and Railsback, unpublished manuscript): over a wide range of parameter values, the negative effects of turbidity on growth (and consequently, reproduction) outweighed the positive effects on predation risk.

\section{Advantages and Drawbacks of the ABM Approach}

\subsection{Advantages}

Assuming that we have the option to make an ABM, what are the key advantages of this approach in ecotoxicology? The most important characteristic of ABMs is that we deal explicitly with spatiotemporal factors, and this coupled with the simple fact that toxicants are rarely distributed evenly in space and time in the real world is a major step forward in realism.

However, this is only half of the story. ABMs integrate the information in heterogeneous environments with the behavior of the agents, since ABMs pose a mechanistic approach. This is clearly demonstrated by the skylark and mechanical weeding example where integration of the management, weather, and skylark ecology and behavior provided the necessary understanding of the system to prescribe nondamaging weeding practices. This integration also allows the consideration of multiple stressors (example 2). Here again, the fact that the ABM integrated the impacts of different stressors with the animal ecology and behavior gave rise to important population-level responses. While consideration of multiple stressors might not be straightforward from a regulatory perspective, it is an area where ABMs could make a major contribution.

Probably the best example of the integrational power of ABMs is the vole example (example 3), which shows the use of an ABM as a virtual laboratory allowing a very wide range of factors to be modified separately or in unison and their impacts compared. This example also illustrates the point about flexibility in ABMs. The problem definition in the vole example required incorporation of individual-based genetic transfer of information due to the epigenetic impact of the pesticide, which in isolation could have been achieved using traditional population genetic approaches. However, this was further complicated 
by the behavioral ecology and individual-level impact of the pesticide. These factors include strong territorial behavior, high fecundity, and local habitat-dependent dispersal in a structurally complex and variably permeable (to dispersing voles) landscape, together with spatiotemporal variation in the distribution of the stressor and variable phenotypic and toxicological responses at the individual level.

It is hard to imagine a non-ABM approach that could integrate all of these aspects in a natural way and yet still provide a simple intuitive experimental system for manipulation and testing. This type of "virtual laboratory" approach has a huge potential in increasing our understanding of biological systems and their responses to toxic stressors. In fact, these approaches are already being used to tackle theoretical population ecology problems in spatially heterogeneous environments [76].

When used to evaluate policy changes, ABM results may often contraindicate a reductionist approach (as shown with the ALMaSS examples earlier). In the real world where so many factors interact it would be common sense to consider the changes in farm management that would result from any policy change, and the use of ABMs should be no different. Although ABMs can become very large and complex they are not capable of simulating systems to such a degree that a single model can encompass all ecological and socioeconomic aspects. However, integration of a range of multidisciplinary models so that inputs to ABMs are as realistic as possible is achievable. For example, Dalgaard et al. [77] linked socioeconomic, nitrogen-budgeting, hydrological, and ecological models together to assess land management scenarios. The flexibility of the complex ABM approach facilitates this process.

Information-rich systems such as the Army Risk Assessment Modeling System (ARAMS) [78] would be ideal candidates to take advantage of agent-based technology. This system already has a wildlife exposure module that uses a simple area use factor to determine exposure, but could be augmented with realistic animal movements and responses to remediation measures.

Another often overlooked advantage of an ABM approach is that the mechanistic detail forces the researcher to consider the system of study from another angle, and perhaps in greater detail than hitherto undertaken. This has the very real benefit of providing a framework for storing current knowledge and identifying areas where research is needed because information is currently lacking.

\subsection{ABMs Versus More Aggregated Population Models}

When considering the advantages and drawbacks of ABMs for ecotoxicological research we are thinking primarily of population-level effects. A common point of contention is whether ABMs are better than simple population models. This point comes up repeatedly at conferences (e.g., see [79]) and therefore we devote a little space to it here.

The question of whether the one type of model is better than the other misses the real point of models, which is to create a representation of a system that allows investigation of the properties of the system and, in some cases, prediction 
of future outcomes. There is nothing innately better about an ABM than, for example, a matrix model of population growth; the two types of model are different and meant for different purposes. A matrix model [80] is a mathematical representation of the current state of the population. Unless its parameters are allowed to vary, it cannot be used for prediction, but only for projection as to whether the population will grow or decline. An ABM, on the other hand, can make predictions because its components alter their states and behaviors in response to changing input variables.

This does not mean that the ABM is better than a matrix model. The ABM cannot be parameterized using the same parameters as the matrix model; it cannot be constructed as quickly as a mathematical model, and it is always more difficult to understand. Choice of model type depends on the resources available and the purpose of the analysis, and it is even less clear cut as we move up the continuum of increasing realism from scalar population models to spatially structured models such as metapopulation models. Here, the purposes of the two model types may overlap, but several factors affect choice of model type. There may be constraints of data availability that dictate a simple model structure, or other constraints such as on development time, available computational power, or even technical ability, which would dictate a simpler model. If such constraints are not important, then there is a common sense link between the accuracy of a model and the degree to which it represents reality (i.e., its realism), but at some point the generality of the model will be reduced as we make the model too specific. Tradeoffs exist between the accuracy of the model, the resources required to build it, and the desired generality [81]. There is no one solution to this problem; each application must be evaluated in its own right. The criteria, however, used for choosing a certain model should be made explicit in any application.

\subsection{Drawbacks}

\subsubsection{Presumed Drawbacks}

Some commonly heard arguments against increasing realism and therefore complexity in models, and by extension to increasing realism in risk assessment are as follows:

Increasing realism decreases generality. This argument probably has its roots with Levins [81], although it is a common general principle. To determine whether this is a drawback or not depends on how general we want our model to be. If our question is specific then a general model is likely to be imprecise (e.g., the use of TER and fixed threshold values for all species in pesticide regulation to predict risk in example 1). In ecotoxicology "general" models are unsatisfactory because there is no general target/nontarget organism, mode of action, or route of exposure. When constructing ABMs generality is not the aim per se; here we usually try to capture the essence of a specific system or class of systems, rather than a generality. However, generalities can be achieved if we evaluate our specific model over a sufficiently wide range of conditions. In principle, the explora- 
tion of carefully defined scenarios in ABMs could provide a sensitivity analysis of the probabilities of adverse effects as well as general rules. For example, in the vole (example 3) interactions between the different landscape structural factors could be evaluated in order to create general rules about pesticide impacts and habitat connectivity.

Adding detail makes the creation and testing of general ecological principles difficult. Not to be confused with a criticism of adding unnecessary detail, this is related to the generality argument, but is fundamentally flawed in that it assumes that we need generalities, that is, simplifications, before developing and testing theories. Surely theories are best derived from patterns emerging from as many varied and detailed observations as possible [16]. So given enough examples of specific systems (such as realistic ABMs) to experiment with, greater insight into general theories or even new paradigms may develop. This goes to the heart of the promise of complexity science and ought not to be perfunctorily dismissed.

Detailed models are unnecessarily complex. Naturally adding detail to a model without good reason would be foolish, because every additional detail causes additional work. So, as for other models the principle of parsimony holds for ABMs. We might use patterns to get ideas about optimal model complexity (see [75]), but ultimately it is the task of model analysis to see how much a model can be simplified while keeping its potential to serve its purpose. However, if we consider complexity in the same way, complexity has a price in terms of increased work in adding model details, but a distinct benefit in terms of richness, which we can utilize for testing, validation, and prediction [19].

Increasing realism leads to a loss of precision. This argument is based upon a traditional statistical approach to modeling. In a mathematical model the error in the prediction is related to the error terms in the parameter inputs in a predictable manner, and this can be propagated or compounded in complex models. While true of a mathematical construct this concept does not necessarily hold for complex systems in which checks and balances stabilize the outputs. It is especially untrue of models constructed using a pattern-oriented approach (see later), whereby error propagation is constrained by the form of model testing [82]. In fact, biological systems in general have sloppy parameter spaces, and focus should, therefore, be on predictions rather than parameter values and their errors [83]. This is incidentally also one of the reasons why these models do not result in deterministic chaos, which is another commonly held, but misinformed belief.

\subsubsection{Real Drawbacks}

There are, however, a number of much more significant drawbacks when considering building ABMs. The drawbacks of constructing and using an ABM approach, especially a comprehensive approach like ALMaSS, can be summed by the phrase "When you can change anything you have to consider everything." In considering "everything" you need both to be able to generate plausible mechanisms for interactions that must all be defined and to locate or generate data to support the parameterizing of these. In building or modifying the model the in- 
teractions must be considered again since what on the face of it may be a simple change can, in fact, have far-reaching consequences. The same is true of building a scenario after the model is finished; simply accepting default values may be counterproductive, for example, applying a reductionist approach to pesticide limitation as in examples 2 and 4.

The difficulties of model construction are already mentioned earlier. The complexity of the system means that the technical demands placed on the developer are higher than those typically placed on the ecological modeler. These demands are comparable to the technical skills required by other specialist branches of natural sciences such as biostatistics or molecular ecology, the difference being that there are few schools of computational biology, and so suitably qualified staff may be hard to find. This may be a major drawback to actually implementing an ABM approach.

Perhaps the biggest drawback to the increased use of ABM models in scientific disciplines in general is simply the fact that they are new. This means that ABMs lack some important characteristics compared with other modeling approaches, these being a rigorous theoretical basis and a standardized approach to construction, testing, and communication of models. In fact, the emergence of theory is a rapidly developing area under the auspices of complexity science. Complexity science aims to describe, explain, and control the collective objects and phenomena emerging at a particular spatiotemporal scale from the simpler interactions of their components at a finer scale. The search for a general theory to simplify understanding of complex systems is, however, elusive. For example, one general theory that might have been useful to describe the emergent patterns of multiagent systems is the theory of self-organized criticality [84]. However, this general theory seems not to have fulfilled its original promise and is perhaps better viewed as a way of sketching the essential structure of a system [85]. Seen in this light, ABMs might fulfill the role of filling in the mechanistic details in system functioning while the search for unifying principles continues at a higher level of organization.

Development of methods for communication and testing of ABMs has started, but is still in its infancy. There is a widely held view that models of this complexity are difficult, if not impossible, to validate. However, one emerging approach to validation is pattern-oriented modeling [75], which includes as a main element inverse modeling for parameterization $[82,86]$ whereby multiple field data patterns are used to simultaneously filter combinations of parameter values and model structures in order to achieve the twin aims of testing the behavior of the agents in the model and of reducing parameter uncertainty. The greater the number of real-world patterns that can be simulated concurrently, the greater the confidence in the model, and typically the smaller the possible parameter space. Pattern-oriented modeling is a new approach and so examples are few and far between (e.g., $[42,87,88])$, and as yet no structured protocols exist for carrying out an analysis. However, the basic approach is well described [89] and would be easily adaptable to an ecotoxicological problem, especially where large-scale field data are available from monitoring studies or field trials. So rather than being seen as a drawback, the novelty of pattern-oriented modeling could be seen as a challenge and an opportunity to develop the science and use of ABMs further. 
Difficulty in communication of ABMs is a major drawback to their acceptance and general accessibility to nonspecialists. This seems paradoxical to some extent since good ABM construction practice is to use the ecological system to be modeled as the primary metaphor [16]. It follows then that explaining the model to ecologists ought to be relatively simple. This can indeed be the case at a superficial level, but description of the detailed choices made in construction and parameterization is far from simple. The two most critical sources of model documentation are the written model description and the source code; however, for ABMs these documents can be very large and are not usually easy to read. One approach suggested is to standardize the description such that once a reader has encountered a number of such descriptions familiarity increases transparency. This is the concept behind the ODD protocol (overview, design concepts, and details) of Grimm et al. [24] and Polhill et al. [90].

The idea of the ODD protocol is to define a fixed sequence in which different levels and elements of a model are described to allow the reader a quick overview of what the model is and what it does, that is, its structure and processes, without having to consider any detail at first. Then, important concepts underlying the design are discussed, for example, how adaptive behavior was represented, and how and why stochasticity was included. Finally, details of the model's implementation are provided. It can be useful, or even necessary, to present the actual code by which a certain process was represented. Thus, the separation of "overview" and "detail" takes into account that some readers are more interested in the overall structure and rationale of the model, for example, the ecotoxicologist, while others want to know the details of the model's implementation, for example, if they have to assess the model as a reviewer for a scientific journal or a regulatory authority. ODD seems to gain ground in the literature but still is in its infancy and under development [14]. It can be difficult to apply it to ABM frameworks such as ALMaSS or FEARLUS [90] because the distinction between a specific model and the framework is not always easy to draw.

\section{The Future of ABMs in Ecotoxicology}

The examples of ABMs in ecotoxicology demonstrate the utility of the ABM approach and highlight that the system response is not easily predictable in advance due to the complex nature of the systems under study. If we do not include multiple stressors we can underestimate risks (example 2), and without evaluating the landscape structure and details of the toxicology of the stressor we also risk inaccurate prediction of the population impact (example 3). Even socioeconomic factors cannot be ignored in any but the most experimental of scenarios (example 4). It seems that almost all factors are important, and that is probably the cause for concern.

All is not lost however. If ABMs can be used to demonstrate that these effects are important, they can also be used to investigate the way these factors interact and thus increase our understanding of the system. In doing so and adding to the examples here, one could imagine an ABM/ecotoxicology utopia where series of representative landscapes were continually updated as agricultural practices change, and farmers responded to socioeconomic drivers and altered their 
management in response to these and weather variables. Aquatic and terrestrial environments would be combined in such a simulation, and surface and ground water flow of pesticides and fertilizers would be modeled. Entire suites of nontarget species could be modeled in these landscapes and whenever a new pesticide or policy change was to be tested it could be done against a well-documented comprehensive simulation of a real system with all the complexities of multiple stressors, varying crop coverage and farmer behavior, and landscape structure.

This would be a far cry from testing whether a TER value was less than 5 , and while it might sound far fetched the technology to accomplish it already exists. Models of all basic subcomponents of the system exist, and hardware is easily capable of running such a system. For instance, ALMaSS can be run on a standard PC with one processing core while research computing facilities now exist with computers having $>11,000$ parallel processor cores [91]. What would be needed would be the resources and the will to construct and maintain such a model. On the other hand, it is important to keep in mind also that simpler ABMs and matrix and differential equation models all have their place. Ideally, such simpler models will be more or less directly linked to more complex ABMs such as the ALMaSS models to achieve a kind of "theoretical validation" of the complex model.

Even without embarking on such a project, the fact that it can now be feasibly imagined suggests that the future of ABMs in ecotoxicology is rosy, and naturally much can be achieved with the models we already have. It is our hope then that, as in other scientific disciplines, ABM development in ecotoxicology is going to be swift and exciting.

\section{References}

1. Folcik VA, An GC, Orosz CG (2007) The basic immune simulator: An agent-based model to study the interactions between innate and adaptive immunity. Theor Biol Med Model 4: 39 . Available at http://www.tbiomed.com/content/4/1/39

2. Fossett M, Senft R (2004) SIMSEG and generative models: A typology of modelgenerated segregation patterns. Proceedings of the Agent 2004 Conference on Social Dynamics: Interaction, Reflexivity and Emergence, Chicago, IL, 39-78. Available at http://www.agent2005. anl.gov/Agent2004.pdf

3. Redfish (2008) http://www.redfish.com/stadium/

4. Chen X, Zhan FB (2008) Agent-based modelling and simulation of urban evacuation: Relative effectiveness of simultaneous and staged evacuation strategies. J Oper Res Soc 59: 25-33

5. Anwar SM, Jeanneret CA, Parrott L, Marceau DJ (2007) Conceptualization and implementation of a multi-agent model to simulate whale-watching tours in the St. Lawrence Estuary in Quebec, Canada. Environ Model Softw 22: 1775-1787

6. Mikler AR, Venkatachalam S, Ramisetty-Mikler S (2007) Decisions under uncertainty: A computational framework for quantification of policies addressing infectious disease epidemics. Stoch Environ Res Risk A 21: 533-543

7. Muller G, Grebaut P, Gouteux JP (2004) An agent-based model of sleeping sickness: Simulation trials of a forest focus in southern Cameroon. CR Biol 327: 1-11

8. Brede M, Boschetti F, McDonald D (2008) Strategies for resource exploitation. Ecol Complex 5: $22-29$

9. Blaum N, Wichmann MC (2007) Short-term transformation of matrix into hospitable habitat facilitates gene flow and mitigates fragmentation. J Anim Ecol 76: 1116-1127 
10. Mathevet R, Bousquet F, Le Page C, Antona M (2003) Agent-based simulations of interactions between duck population, farming decisions and leasing of hunting rights in the Camargue (Southern France). Ecol Model 165: 107-126

11. Satake A, Leslie HM, Iwasa Y, Levin SA (2007) Coupled ecological-social dynamics in a forested landscape: Spatial interactions and information flow. J Theor Biol 246: 695-707

12. DeAngelis DL, Gross LJ (1992) Individual-based models and approaches in ecology: Populations, communities and ecosystems. Chapman and Hall, New York

13. Louzoun Y, Solomon S, Atlan H, Cohen IR (2001) Modeling complexity in biology. Phys A 297: $242-252$

14. Grimm V (2008) Individual-based models. In: Jørgensen SE, Fath BD (eds), Ecological Models, Vol. [3] of Encyclopedia of Ecology, Elsevier, Oxford, 5: 1959-1968

15. Grimm V (1999) Ten years of individual-based modelling in ecology: What have we learned and what could we learn in the future? Ecol Model 115: 129-148

16. Grimm V, Railsback SF (2005) Individual-based modelling and ecology. Princeton University Press, Princeton, NJ

17. DeAngelis DL, Mooij WM (2005) Individual-based modeling of ecological and evolutionary processes. Annu Rev Ecol Evol Syst 36: 147-168

18. Van den Brink P, Baveco JM, Verboom J, Heimbach F (2007) An individual-based approach to model spatial population dynamics of invertebrates in aquatic ecosystems after pesticide contamination. Environ Toxicol Chem 26: 2226-2236

19. DeAngelis DL, Mooij WM (2003) In praise of mechanistically-rich models. In: Canham CD, Cole JJ, Lauenroth WK (eds) Models in ecosystem science. University Press, Princeton, NJ

20. Holland EP, Aegerter JN, Dytham C, Smith GC (2007) Landscape as a model: The importance of geometry. PloS Comput Biol 3: 1979-1992

21. Jepsen JU, Baveco JM, Topping, CJ, Verboom J, Vos CC (2005) Evaluating the effect of corridors and landscape heterogeneity on dispersal probability: A comparison of three spatially explicit modelling approaches. Ecol Model 181: 445-459

22. DeAngelis DL, Cox DK, Coutant CC (1980) Cannibalism and size dispersal in young-of-theyear largemouth bass - Experiment and model. Ecol Model 8: 133-148

23. Topping CJ, Rehder MJ, Mayoh BH (1999) Viola: A new visual programming language designed for the rapid development of interacting agent systems. Acta Biotheor 47: 129-140

24. Grimm V, Berger U, Bastiansen F, Eliassen S, Ginot V, Giske J, Goss-Custard J, Grand T, Heinz SK, Huse G, Huth A, Jepsen JU, Jorgensen C, Mooij WM, Muller B, Pe'er G, Piou C, Railsback SF, Robbins AM, Robbins MM, Rossmanith E, Ruger N, Strand E, Souissi S, Stillman RA, Vabo R, Visser U, DeAngelis DL (2006) A standard protocol for describing individual-based and agent-based models. Ecol Model 198: 115-126

25. Caron-Lormier G, Humphry RW, Bohan DA, Hawes C, Thorbek P (2008) Asynchronous and synchronous updating in individual-based models. Ecol Model 212: 522-527

26. Crooks AT (2007) The repast simulation/modelling system for geospatial simulation. Centre for Advanced Spatial Analysis (University College London), London, UK.Working Paper 123. Available at http://www.casa.ucl.ac.uk/working papers/paper123.pdf

27. Wilensky U (1999) NetLogo. Center for Connected Learning and Computer-Based Modeling, Northwestern University, Evanston, IL. Available at http:/ / ccl.northwestern.edu/netlogo

28. Swarm (2006) Swarm: A platform for agent-based models. Available at http://www.swarm.org/

29. Topping CJ, Hansen TS, Jensen TS, Jepsen JU, Nikolajsen F, Odderskær P (2003) ALMaSS, an agent-based model for animals in temperate European landscapes. Ecol Model 167: 65-82

30. Topping CJ, Odderskær P (2004) Modeling the influence of temporal and spatial factors on the assessment of impacts of pesticides on skylarks. Environ Toxicol Chem 23: 509-520

31. Topping CJ, Sibly RM, Akcakaya HR, Smith GC, Crocker DR (2005) Risk assessment of UK skylark populations using life-history and individual-based landscape models. Ecotoxicology 14: 925-936

32. Bilde T, Topping C (2004) Life history traits interact with landscape composition to influence population dynamics of a terrestrial arthropod: A simulation study. Ecoscience 11: 64-73 
33. Thorbek P, Topping CJ (2005) The influence of landscape diversity and heterogeneity on spatial dynamics of agrobiont linyphiid spiders: An individual-based model. Biocontrol 50: $1-33$

34. Jepsen JU, Topping CJ (2004) Modelling roe deer (Capreolus capreolus) in a gradient of forest fragmentation: Behavioural plasticity and choice of cover. Can J Zool 82: 1528-1541

35. Fuller RJ, Gregory RD, Gibbons DW, Marchant JH, Wilson JD, Baillie SR, Carter N (1995) Population declines and range contractions among lowland farmland birds. Conserv Biol 9: 1425-1441

36. Chamberlain DE, Fuller RJ, Bunce RGH, Duckworth JC, Shrubb M (2000) Changes in the abundance of farmland birds in relation to the timing of agricultural intensification in England and Wales. J Appl Ecol 37: 771-788

37. Odderskær P, Topping CJ, Petersen MB, Rasmussen J, Dalgaard T, Erlandsen M (2006) Ukrudtsstriglingens effekter på dyr, planter og ressourceforbrug. Miljøstyrelsen, Bekæmpelsesmiddelforskning fra Miljøstyrelsen 105. Available at http://www2.mst.dk/Udgiv/publikationer/2006/87-7052-343-6/pdf/87-7052-344-4.pdf

38. Schl"apfer A (1988) Populations"okologie der Feldlerche Alauda arvensis in der intensiv genutzten Agrarlandschaft. Der Ornitologische Beobachter 85: 309-371

39. JennyM(1990) Populationsdynamic der Feldlerche Alauda arvensis in einer intensiv genutzten Agrarlandschaft des Sweizerischen Mittellandes. Der Ornitilogischer Beobachter 87: 153-163

40. Daunicht WD (1998) Zum Einfluss der Feinstruktur in der Vegatation auf die Habitatwahl, Habitatnutzung, Siedlungsdichte und Populationsdynamik von Feldlerchen (Alauda arvensis) in großparzelligem Ackerland. Phd Thesis. University of Bern, Bern

41. Navntoft S, Petersen BS, Esbjerg P, Jensen A, Johnsen I, Kristensen K, Petersen PH, Ørum JE (2007) Effects of mechanical weed control in spring cereals - Flora, fauna and economy. Danish Environmental Protection Agency, Pesticides Research No. 114

42. Wiegand K, Saltz D, Ward D, Levin SA (2008) The role of size inequality in self-thinning: A pattern-oriented simulation model for and savannas. Ecol Model 210: 431-445

43. Thorbek P, Bilde T (2004) Reduced numbers of generalist arthropod predators after crop management. J Appl Ecol 41: 526-538

44. Den Boer PJ (1990) The survival value of dispersal in terrestrial arthropods. Biol Conserv 54: 175-192

45. Errington PL (1934) Vulnerability of bob-white populations to predation. Ecology 15: $110-127$

46. Dalkvist T, Topping CJ, Forbes VE (2009) Population-level impacts of pesticide-induced chronic effects on individuals depend more on ecology than toxicology. Ecotoxicol Environ Safety, doi: 10.1016/j.ecoenv.2008.10.002

47. Anway MD, Cupp AS, Uzumcu M, Skinner MK (2005) Epigenetic transgenerational actions of endocrine disruptors and mate fertility. Science 308: 1466-1469

48. Anway MD, Leathers C, Skinner MK (2006) Endocrine disruptor vinclozolin induced epigenetic transgenerational adult-onset disease. Endocrinology 147: 5515-5523

49. Hansson L (1977) Spatial dynamics of field voles Microtus agrestis in heterogeneous landscapes. Oikos 29: 593-644

50. Evans DM, Redpath SM, Elston DA, Evans SA, Mitchell RJ, Dennis P (2006) To graze or not to graze? Sheep, voles, forestry and nature conservation in the British uplands. J Appl Ecol 43: 499-505

51. Smidt NM, Olsen H, BildsøeM, Sluydts V, Leirs H (2005) Effects of grazing intensity on small mammal population ecology in wet meadows. Basic Appl Ecol 6: 57-66

52. Jensen TS, Hansen TS (2001) Effekten af husdyrgræsning på småpattedyr. In: Pedersen L B, Buttenschøn R, Jensen T S (eds) Græsning på ekstensivt drevne naturarealer - Effekter på stofkredsløb og naturindhold. Skov \& Landskab, Hørsholm, Parkog Landskabsserien 34: $107-121$

53. Bell G, Lechowicz MJ, Appenzeller A, Chandler M, DeBlois E, Jackson L, Mackenzie B, Preziosi R, Schallenberg M, Tinker N (1993) The spatial structure of the physical environ- 
ment. Oecologia 96: 114-121

54. Clifford PA, Barchers DE, Ludwig DF, Sielken RL, Klingensmith JS, Graham RV, Banton MI (1995) An approach to quantifying spatial components of exposure for ecological risk assessment. Environ Toxicol Chem 14: 895-906

55. Purucker ST, Welsh CJE, Stewart RN, Starzec P (2007) Use of habitat-contamination spatial correlation to determine when to perform a spatially explicit ecological risk assessment. Ecol Model 204: 180-192

56. Jacobsen LB, Frandsen SE (1999) Analyse af de sektor-og samfundsøkonomiske konsekvenser af en reduktion af forbruget af pesticider i dansk landbrug. The Ministry of Food, Agriculture and Fisheries, Danish Research Institute of Food Economics, Denmark, 104

57. Topping CJ (2005) The impact on skylark numbers of reductions in pesticide usage in Denmark. Predictions using a landscape-scale individual based model. National Environmental Research Institute, Denmark, NERI Technical Report 527: 33. Available at http://technicalreports.dmu.dk

58. Goss-Custard JD, Durell SEALD (1990) Bird behaviour and environmental planning: Approaches in the study of wader populations. Ibis 132: 273-282

59. Goss-Custard JD, Caldow RWG, Clarke RT, Durell SEALD, Sutherland WJ (1995) Deriving population parameters from individual variations in foraging behaviour. I. Empirical gametheory distribution model of oystercatchers Haematopus ostralegus feeding on mussels Mytilus edulis. J Anim Ecol 64: 265-276

60. Sutherland WJ (1996) From individual behaviour to population ecology. Oxford University Press, Oxford

61. Goss-Custard JD, Sutherland WJ (1997) Individual behaviour, populations and conservation. In: JR Krebs, NB Davies (eds) Behavioural ecology: An evolutionary approach. Blackwell Science, Oxford

62. Stillman RA, Goss-Custard JD, West AD, Durell S, Caldow RWG, McGrorty S, Clarke RT (2000) Predicting mortality in novel environments: Tests and sensitivity of a behaviourbased model. J Appl Ecol 37: 564-588

63. Stillman RA, Goss-Custard JD, West AD, Durell S, McGrorty S, Caldow RWG, Norris KJ, Johnstone IG, Ens BJ, Van der Meer J, Triplet P (2001) Predicting shorebird mortality and population size under different regimes of shellfishery management. J Appl Ecol 38: 857-868

64. Stillman RA, Caldow RWG, Durell SEALD, West AD, McGrorty S, Goss-Custard JD, PerezHurtado A, Castro M, Estrella SM, Masero JA, Rodr'iguez-Pascual FH, Triplet P, Loquet N, Desprez M, Fritz H, Clausen P, Ebbinge BS, Norris K,Mattison E (2005) Coast bird diversity maintaining migratory coastal bird diversity: Management through individual-based predictive population modelling. Centre for Ecology and Hydrology for the Commission of the European Communities, UK

65. Stillman RA, West AD, Goss-Custard JD, McGrorty S, Frost NJ, Morrisey DJ, Kenny AJ, Drewitt A (2005) Predicting site quality for shorebird communities: A case study on the Humber estuary, UK. Mar Ecol Prog Series 305: 203-217

66. Goss-Custard JD, Burton NHK, Clark NA, Ferns PN, McGrorty S, Reading CJ, Rehfisch MM, Stillman RA, Townend I, West AD, Worrall DH (2006) Test of a behavior-based individualbased model: Response of shorebird mortality to habitat loss. Ecol Appl 16: 2215-2222

67. Railsback SF, Lamberson RH, Harvey BC, Duffy WE (1999) Movement rules for individualbased models of stream fish. Ecol Model 123: 73-89

68. Railsback SF (2001) Getting "results": The pattern-oriented approach to analyzing natural systems with individual-based models. Nat Resour Model 14: 465-474

69. Railsback SF (2001) Concepts from complex adaptive systems as a framework for individualbased modelling. Ecol Model 139: 47-62

70. Railsback SF, Harvey BC (2001) Individual-based model formulation for cutthroat trout, Little Jonas Creek, California. General Technical Report PSW-GTR-182. Pacific Southwest Research Station, Forest Service, U.S. Department of Agriculture, Albany, CA

71. Railsback SF, Harvey BC (2002) Analysis of habitat selection rules using an individual-based model. Ecology 83: 1817-1830 
72. Railsback SF, Harvey BC, Lamberson RH, Lee DE, Claasen NJ, Yoshihara S (2002) Population-level analysis and validation of an individual-based cutthroat trout model. Nat Resour Model 14: 465-474

73. Railsback SF, Stauffer HB, Harvey BC (2003) What can habitat preference models tell us? Tests using a virtual trout population. Ecol Appl 13: 1580

74. Van Winkle W, Jager HI, Railsback SF, Holcomb BD, Studley TK, Baldrige JE (1998) Individual-based model of sympatric populations of brown and rainbow trout for instream flow assessment: Model description and calibration. Ecol Model 110: 175-207

75. Grimm V, Revilla E, Berger U, Jeltsch F, Mooij WM, Railsback SF, Thulke HH, Weiner J, Wiegand T, DeAngelis DL (2005) Pattern-oriented modeling of agent-based complex systems: Lessons from ecology. Science 310: 987-991

76. Sibly RM, Nabe-Nielsen J, Forchhammer MC, Forbes VE, Topping CJ (2008) On population dynamics in heterogeneous landscapes. Ecol Lett 17: 10.1023/A:1027390600748

77. Dalgaard T, Kjeldsen T, Rasmussen BM, Fredshavn JR, M“unier B, Schou JS, Dahl M, Wiborg IA, Nørmark P, Hansen JF (2004) ARLAS' scenariesystem. Et grundlag for helhedsorienterede konsekvensvurdringer af ændringer i arealanvendelsen. In: Hansen JF (ed) Arealanvendelse og landskabsudvikling Fremtidsperspektiver for natur, jordbrug, miljø og arealforvaltning. Danmarks Jordbrugsforskning, Markbrug, 110, 97-128 (in Danish with English summary). Available at: http://web.agrsci.dk/djfpublikation/djfpdf/djfma110.pdf

78. Dortch MS, Gerald JA (2004) Recent advances in the army risk assessment modeling system. In: Whelan G (ed) Brownfields, multimedia modeling and assessment. WIT Press, Southampton, UK. Available at: http://el.erdc.usace.army.mil/arams/pdfs/arams04-advance. pdf

79. Thorbek P, Forbes V, Heimbach F, Hommen U, Thulke HH, van den Brink P,Wogram J, Grimm V (2008) Ecological models in support of regulatory risk assessments of pesticides: Developing a strategy for the future. Integr Environ Assess Manag 5: 1

80. Caswell H (2001) Matrix population models: Construction, analysis, and interpretation. Sinauer Associates, Sunderland, MA

81. Levins R (1966) Strategy of model building in population biology. Am Sci 54: 421-431

82. Wiegand T, Jeltsch F, Hanski I, Grimm V (2003) Using pattern-oriented modeling for revealing hidden information: A key for reconciling ecological theory and application. Oikos 100: 209- 222

83. Gutenkunst RN, Waterfall JJ, Casey FP, Brown KS, Myers CR, Sethna JP (2007) Universally sloppy parameter sensitivities in systems biology models. PloS Comput Biol 3: 1871-1878

84. Bak P (1997) How nature works: The science of self-organised criticality. University Press, Oxford

85. Frigg R (2003) Self-organised criticality -What it is and what it isn't. Stud His Philos Sci 34A: 613-632

86. Tarantola A (1987) Inverse problem theory: Methods for data fitting and model parameter estimation. Elsevier, New York

87. Lambert P, Rochard E (2007) Identification of the inland population dynamics of the European eel using pattern-oriented modelling. Ecol Model 206: 166-178

88. Rossmanith E, Blaum N, Grimm V, Jeltsch F (2007) Pattern-oriented modelling for estimating unknown pre-breeding survival rates: The case of the lesser spotted woodpecker (Picoides minor). Biol Conserv 135: 555-564

89. Kramer-Schadt S, Revilla E,Wiegand T, Grimm V (2007) Patterns for parameters in simulation models. Ecol Model 204: 553-556

90. Polhill GJ, Parker DC, Brown DG, Grimm V (2008) Using the ODD protocol for describing three agent-based social simulation models of land use change. J Artif Soc Sci Sim 11(2/3) http://jasss.soc.surrey.ac.uk/11/2/3.html

91. http://www.hector.ac.uk 